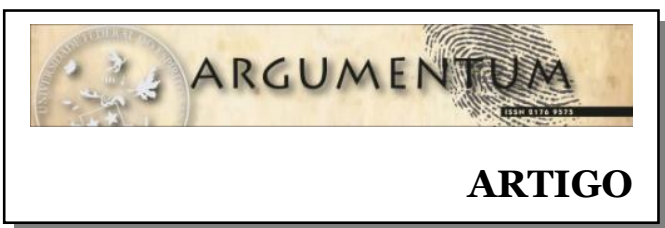

\title{
Repressão estatal e controle da pobreza no Brasil contemporâneo
}

\author{
State repression and poverty control in contemporany Brazil
}

Nathália de Lourdes Fernandes CORREIA*

https://orcid.org/o0oo-0002-5501-3752

\section{Reivan Marinho de SOUZA**}

https://orcid.org/o0oo-0002-3919-9454

\begin{abstract}
Resumo: Este artigo propõe-se a desvelar as determinações econômico-sociais que têm conduzido ao aprofundamento da repressão do Estado em direção à pobreza no Brasil. O Estado mantém uma indissociável relação com a economia e, para cumprir historicamente sua função social, pode intervir de forma repressiva ou coerciva. Verifica-se na atualidade, com a crise estrutural, conforme validado por dados empíricos, que o aumento da ação repressiva do Estado no Brasil revela o encarceramento em massa, o surgimento de novas medidas coercitivas e o aumento de mortes por intervenção policial, como consequência das transformações societárias, do desemprego crônico e da pobreza.
\end{abstract}

Palavras-chave: Repressão Estatal. Capitalismo. Pobreza. Crise estrutural.

Abstract: This article proposes to unveil the economic and social determinations that have led to the deepening of the State's repression towards poverty in Brazil. The State maintains an inseparable relationship with the economy and to fulfill its social function historically it can intervene in a repressive or coercive way. Currently, with the structural crisis, as validated by the empirical data, the increase in the State's repressive action in Brazil reveals a massive incarceration in the country, the emergence of new repressive measures and the increase in deaths due to police intervention, as consequence of societal changes, chronic unemployment and poverty.

Keywords: State Repression. Capitalism. Poverty. Structural crisis.

Submetido em: 29/6/2020. Revisado em: 24/9/2020. Aceito em: 28/9/2020.

\footnotetext{
* Assistente Social. Mestre em Serviço Social pelo Programa de Pós-Graduação/ PPGSS da Faculdade de Serviço Social, Universidade Federal de Alagoas. (UFAL) Campus A. C. Simões - Av. Lourival Melo Mota, S/N, Tabuleiro do Martins, Maceió (AL), CEP: 57072-970. E-mail: nathalia.fernandesc@hotmail.com.

** Assistente Social. Doutora em Serviço Social. Professora Associada do Curso de Graduação e do Programa de Pós-Graduação/ PPGSS da Faculdade de Serviço Social, Universidade Federal de Alagoas. (UFAL) Campus A. C. Simões - Av. Lourival Melo Mota, S/N, Tabuleiro do Martins, Maceió (AL), CEP: 57072-970. E-mail: reivan.souza@fsso.ufal.br, reivansouza@yahoo.com.br. copiar e redistribuir o material em qualquer suporte ou formato, bem como adaptar, transformar e criar a partir deste material para qualquer fim, mesmo que comercial. O licenciante não pode revogar estes direitos desde que você respeite os termos da licença.
} 


\section{Introdução}

$\mathrm{O}$ fenômeno de intensificação da ação repressiva do Estado voltada para a pobreza no Brasil tem sido destaque na produção científica nos últimos anos. O posto alcançado se deve aos dados irrefutáveis no que se refere ao encarceramento em massa no Brasil e no mundo, ao recrudescimento das legislações brasileiras, às atuais propostas da Comissão de Segurança Pública, ao número crescente de mortes por intervenção policial, à intervenção federal realizada no Rio de Janeiro no ano de 2018, dentre outros fatos que são expressões concretas do referido fenômeno. Frente a essa realidade, o objetivo deste artigo é explicitar, de forma genérica, as determinações econômicas, políticas e sociais que têm conduzido à utilização crescente do aparato repressivo do Estado para controle da pobreza no Brasil. Propõe-se, portanto, a evidenciar a tendência, e não as formas específicas, de repressão estatal.

Com base na perspectiva marxiana, apreende-se que o fenômeno em questão não decorre do afastamento de um "Estado Social" e do advento de um "Estado Penal", como sugere a corrente de pensamento hegemônica na análise do tema, mas diz respeito às atuais alterações realizadas na base material do sistema, que exigem do Estado uma ação mais repressiva para controlar a pobreza, do mesmo modo que já requereu, em outro contexto, uma atuação predominantemente consensual. Cabe destacar, inclusive, que essas estratégias estatais - coerção e consenso - convivem no desenvolvimento do capitalismo, o que não impede a predominância de uma ou de outra em determinada conjuntura.

\section{Crise estrutural, pobreza e repressão estatal no Brasil}

O modo de produção capitalista gera contradições que obstaculizam sua expansão; essas contradições expressas nas crises, no entanto, são inerentes ao desenvolvimento desse sistema. Apesar dos danos econômicos e sociais provocados, as crises não representam barreiras à reprodução do capital, pois seus efeitos podem ser contornados a partir de medidas protelatórias no próprio sistema. Essas crises, de natureza cíclica, além de não representarem uma ameaça à expansão e à acumulação do capital, são funcionais ao seu modo de produção, participando da dinâmica capitalista - desenvolvimento, expansão e crise. Assim, as medidas de controle aplicadas pelo Estado não enfrentam as causas dos desequilíbrios entre produção e consumo, são apenas medidas protelatórias que administram temporariamente os efeitos que atravancam a acumulação.

As contradições históricas do capital - fundamento das crises econômicas - são deslocadas e não eliminadas, e se aprofundam historicamente à medida que as saídas outrora utilizadas pelo sistema se esgotam a cada novo ciclo econômico. No final de 1960, o aumento da produção conduz a uma superprodução de mercadorias e, nesse momento, o sistema do capital já não possui mecanismos para deslocar para o futuro as consequências danosas da abundância, e o capitalismo avança para uma fase irreversível de crise estrutural.

Argum., Vitória, v. 12, n. 3, p. 43-57, set./dez. 2020. | ISSN 2176-9575 
Essa crise tem início em 1970, momento em que o sistema do capital já não é "[...] capaz de controlar sua lógica destrutiva, de dar solução aos crescentes problemas sociais e de evitar os impactos desestabilizadores das contradições de sua reprodução ampliada, propagados no interior da própria ordem capitalista" (PANIAGO, 2014, p. 47). O caráter novo dessa crise manifesta-se em quatro aspectos substanciais: 1) Seu caráter é universal, atinge todas as esferas da vida social; 2) seu alcance é global, pois seus impactos abrangem a totalidade dos países; 3) sua escala de tempo é contínua, permanente e não limitada como as crises cíclicas que a precederam; e 4) seu desdobramento é rastejante, o que não significa que futuras convulsões mais violentas possam ser excluídas (MÉSZAROS, 2011, p. 795-796).

As crises cíclicas estavam relacionadas à ativação dos limites relativos/imediatos do sistema do capital, podiam ser superadas, e seus efeitos danosos, minimizados ou contidos. Entretanto, o sistema do capital possui limites absolutos que não podem ser ultrapassados no em seu interior. A crise estrutural do capital revela a ativação desses limites, pois “[...] já não se poderá evitar por muito mais tempo o enfrentamento da questão de como superar os pressupostos estruturais destrutivos do modo estabelecido de controle sociometabólico" (MÉSZAROS, 2011, p. 217).

Um desses limites absolutos é o mais explosivo e está articulado ao aprofundamento da pobreza e às respostas repressivas do Estado sobre ela. Trata-se do desemprego crônico, que se agudiza com a crise estrutural, com a reestruturação capitalista, quando se tenta recuperar as taxas de lucro em queda e controlar o desemprego. Conforme Mészaros, "[...] o remédio para dar seguimento às deficiências e às 'disfunções' devidas ao desemprego crônico em todos os países [...], em rigorosa conformidade aos parâmetros causais do sistema do capital, é visto em termos de 'maior disciplina do trabalho' e 'maior eficiência”' (MÉSZAROS, 2011, p. 211).

Não poderia ser de outro modo, já que a consequência da inovação tecnológica é a redução do trabalho vivo e o aumento do desemprego. Inevitavelmente, nesse círculo vicioso, agrava-se a contradição entre produção e circulação/consumo, pois, quando o capital tolhe a capacidade de compra do trabalhador/consumidor, acaba por recolocar novas contradições contra si mesmo: "De um lado, encontramos o apetite sempre crescente do capital por 'consumidores de massa' enquanto, de outro, a sua necessidade sempre decrescente de trabalho vivo” (MÉSZAROS, 2011, p. 673, grifos do autor). A partir de então, o desemprego torna-se estrutural, porque "[...] as contradições ocorridas em qualquer uma de suas partes específicas complicam e agravam os problemas de outras partes e, consequentemente, da sua totalidade" (MÉSZAROS, 2006, apud COSTA, 2007, p. 7).

Na década de 1970, as consequências devastadoras resultantes da tendência contraditória do capital em expulsar grande número de trabalhadores da indústria nos países centrais atingem os trabalhadores sem qualificação e os qualificados, que se aglutinavam na disputa pelos escassos empregos disponíveis. Em 1994, dados apontavam que $40 \%$ da população dos Estados Unidos era supérflua ao capital: "É como se o exército industrial de reserva fosse o mundo todo" (MÉSZAROS, 2011, p. 326). As alternativas econômicas propostas e as tentativas estatais passam a ser

Argum., Vitória, v. 12, n. 3, p. 43-57, set./dez. 2020. | ISSN 2176-9575 
inférteis porque os problemas do sistema do capital são tão graves que as tentativas de remediá-los não arranham sequer sua superfície. Nessas condições, "[...] ativa-se a 'explosão populacional', sob a forma de desemprego crônico, como um limite absoluto do capital” (MÉSZAROS, 2011, p. 333, grifos do autor). Isso representa um:

[...] perigo sério para a totalidade do sistema, pois se acreditava no passado que o desemprego maciço fosse algo que só afetasse as áreas mais 'atrasadas' e 'subdesenvolvidas' do planeta. [...] não é muito difícil perceber que a multiplicação incontrolável da 'força de trabalho supérflua' representa não apenas uma drenagem enorme de recursos do sistema, mas também uma carga potencialmente explosiva extremamente instável (MÉSZAROS, 2011, p. $342)$.

Evidentemente os reflexos da crise não se restringem à esfera socioeconômica e se manifestam também no campo da política, sendo este um dos seus momentos integrantes. Dessa forma, retoma-se o conhecido ideário liberal, com a defesa da liberdade do mercado. A ideologia neoliberal põe a estabilidade monetária como meta suprema e a contenção de gastos sociais como condição para isso, associada a reformas fiscais e à redução de impostos para altos rendimentos. O neoliberalismo se impõe sobre a sociedade com uma série de medidas, como: reformas da economia e do Estado, liberalização do comércio, privatizações e corte nas políticas sociais. A reestruturação produtiva, com a desregulamentação e a flexibilização das relações de trabalho, é uma das evidências dessas políticas neoliberais que provocam:

1) um desemprego que cresce cronicamente em todos os campos de atividade, mesmo quando é disfarçado como 'práticas trabalhistas flexíveis' - um eufemismo cínico para a política deliberada de fragmentação e precarização da força de trabalho e para a máxima exploração administrável do trabalho em tempo parcial; e 2) uma redução significativa do padrão de vida até mesmo daquela parte da população trabalhadora que é necessária aos requisitos operacionais do sistema produtivo em ocupações em tempo integral (MÉSZAROS, 2011, p. 342).

Configura-se, portanto, a globalização do desemprego e, consequentemente, da pobreza. Com as alterações no "mundo do trabalho", somam-se a essa pobreza os trabalhadores precarizados, como terceirizados, informais, imigrantes e segmentos populacionais vulneráveis. Essas são expressões da questão social ${ }^{1}$ atual, ocasionadas pela crise estrutural, geradoras de uma instabilidade social que não interessa ao sistema, porque vem acompanhada de consequências sociais que caracterizam um limite ao controle sociometabólico do próprio capital. Por isso que, para Mészaros:

\footnotetext{
${ }^{1}$ A "questão social" está diretamente vinculada ao processo de desenvolvimento das forças produtivas no período de expansão da industrialização no século XIX, neste terreno contraditório entre capital e trabalho, onde se encontram as condições econômico-sociais e políticas para a sua emergência. Para Netto (1989), a "questão social” constitui um complexo problemático muito amplo, que abrange o "[...] conjunto de problemas econômicos, sociais, políticos, culturais e ideológicos que cerca a emersão da classe operária como sujeito sociopolítico no marco da sociedade burguesa" (NETTO, 1989, p. 90). Nesse sentido, o fenômeno que assume a aparência da pobreza, violência, desemprego, na verdade, corresponde à "questão social", resultado da necessária e conflituosa contradição entre capital e trabalho, cuja essência está na lei geral da acumulação capitalista, que produz e reproduz essas contradições. O termo "questão social" é grafado pelo autor entre aspas como forma de precaução, em decorrência da utilização tradicional-conservadora na sua gênese.
} 
[...] considerado em si mesmo, o desemprego sempre crescente mina a estabilidade social, trazendo consigo o que até os círculos oficiais reconhecem ser 'consequências indesejáveis', depois de muitos anos de negar que as tendências negativas de desenvolvimento denunciadas tivessem algo a ver com o câncer social que é o desemprego crônico. Elas vão desde uma taxa de criminalidade crescente (especialmente entre os jovens) até denúncias violentas de agravos econômicos e formas de ação direta [...] trazendo o perigo de graves agitações sociais (MÉSZAROS, 2011, p. 342- 343).

Nesse quadro de crise, “[...] as formas de administração da 'questão social' tradicionalmente utilizadas com vistas a atenuar os conflitos perderam o sentido em face da gravidade dos problemas existentes" (PIMENTEL, 2012, p. 117). Nesse contexto atual, o Estado abandona a estratégia de consenso e vai pôr à mostra sua essência potencialmente coercitiva, desenvolvendo novas formas de controle que garantam a estabilidade social tão fundamental para a reprodução ampliada do capital. Por essas razões, desde 1970, identifica-se um crescente uso do aparato repressivo do Estado e do Direito, isto é, do conjunto de acessórios materiais e suas instituições coercitivas e dos corpos especiais de homens armados. Inicialmente, esse fenômeno se configura nos países de capitalismo avançado que aderiram primariamente às políticas neoliberais.

Wacquant (2008) registra um aumento exponencial da população carcerária dos Estados Unidos entre 1975 e 2000, passando de 380 mil a 2 milhões de detentos, submetendo algo em torno de 6,5 milhões de pessoas à supervisão da justiça penal. No entanto, o encarceramento em massa, uma das maiores evidências desse fenômeno, não se restringe a esse país. Salvaguardando as diferenças e as particularidades de cada formação socioeconômica, atravessa em maior ou menor intensidade todas as localidades. Wacquant (1999) expõe a inflação carcerária na União Europeia entre 1983 - 1997, na Tabela 1.

Tabela 1 - Inflação carcerária na Europa entre 1983 - 1997

\begin{tabular}{l|c|c|c|c}
\hline \multicolumn{1}{c|}{ País } & $\mathbf{1 9 8 3}$ & $\mathbf{1 9 9 0}$ & $\mathbf{1 9 9 7}$ & Crescimento \\
\hline Inglaterra/Gales & 43.415 & 50.106 & 61.940 & $43 \%$ \\
\hline França & 39.086 & 47.449 & 54.442 & $39 \%$ \\
\hline Itália & 41.413 & 32.588 & 49.477 & $20 \%$ \\
\hline Espanha & 14.659 & 32.902 & 42.827 & $192 \%$ \\
\hline Portugal & 6.093 & 9.059 & 14.634 & $240 \%$ \\
\hline Holanda & 4.000 & 6.662 & 13.618 & $28 \%$ \\
\hline Bélgica & 6.524 & 6.525 & 8.342 & $49 \%$ \\
\hline Grécia & 3.736 & 4.786 & 5.577 & $18 \%$ \\
\hline Suécia & 4.422 & 4.895 & 5.221 & $6 \%$ \\
\hline Dinamarca & 3.120 & 3.243 & 3.299 & $66 \%$ \\
\hline Irlanda & 1.466 & 2.114 & 2.433 & 20 \\
\hline
\end{tabular}

Fonte: Wacquant (1999).

Mesmo com os discursos democráticos, observa-se uma mediação política cada vez mais autoritária e repressiva para contenção das insatisfações sociais. A intensificação

Argum., Vitória, v. 12, n. 3, p. 43-57, set./dez. 2020. | ISSN 2176-9575 
da ação repressiva do Estado voltada para o controle da pobreza, portanto, está intimamente vinculada à instabilidade socioeconômica provocada pelas transformações societárias desencadeadas pela crise estrutural do capitalismo. Para se sustentar, o capital intensifica a sua destruição em relação à natureza e à humanidade, desemprega e precariza o trabalho. Com efeito, a repressão estatal nada mais é do que uma das estratégias encontradas para administrar o acirramento das contradições sociais inerentes ao sistema que se agravam com sua crise estrutural.

No cenário brasileiro, as consequências da ativação desse limite absoluto ganham relevância em decorrência das suas particularidades históricas, sociais e políticas. Devido ao desenvolvimento tardio do capitalismo no país e à posição que ocupa na divisão internacional do trabalho, de um país heteronômico, periférico, que acumula riqueza em escala exponencial e pobreza alarmante, o Brasil, assim como os demais países da América Latina, é portador de uma desigualdade social profunda, expressa nas imensas disparidades entre seus habitantes em termos de renda, de acesso à educação e a serviços básicos.

A desigualdade social no Brasil possui um dos maiores índices do mundo e se expressa nas diferentes regiões e nos territórios internos das próprias cidades. A concentração de renda se comprova pelos dados de 2017 do Instituto Brasileiro de Geografia e Estatística (IBGE), que revelam que $1 \%$ do grupo formado pelos mais ricos da população brasileira tinha um rendimento médio de $\mathrm{R} \$ 28.040$ mensais, 36,1 vezes acima do que recebia a metade mais pobre da população brasileira, com rendimento médio de R\$ 754 (INSTITUTO BRASILEIRO DE GEOGRAFIA E ESTATÍSTICA, 2017, p. 6).

A particularidade brasileira explica a forma com que a lei geral da acumulação capitalista $^{2}$ opera no país, com a concentração de riquezas nas mãos de uma pequena parcela da população, e a pobreza concentrada na maioria dos brasileiros. É regra no país a falta de saneamento básico, de acesso à habitação, à educação e à saúde; trata-se de uma massa de trabalhadores empregados e desempregados que padecem na pobreza. O enfrentamento do Estado brasileiro às sequelas da "questão social", a

\footnotetext{
2 No capítulo intitulado A Lei Geral da Acumulação Capitalista, Marx (1996) revela a anatomia do pauperismo e sua essência fundamentalmente econômica, enquanto resultado do processo de expansão e acumulação do capital. Segundo o autor, a partir da segunda metade do século XVIII, com o início da Revolução Industrial, ocorre uma alteração qualitativa da composição orgânica do capital, quando a demanda por meios de produção tende a crescer em maior proporção do que a demanda por força de trabalho. Com isso, amplia tendencialmente a força de trabalho a ser dispensada do processo de produção, pois a dinâmica capitalista condena uma parte da classe trabalhadora à ociosidade forçada, produzindo assim um contingente de trabalhadores desempregados que formam um exército industrial de reserva ou superpopulação relativa. Na mais baixa camada social desta superpopulação relativa, se encontra a esfera do pauperismo, um contingente de trabalhadores desempregados aptos para o trabalho que aumenta e diminui em volume a cada crise e restabelecimento do capital. Portanto, o próprio movimento de expansão do capital, ao expulsar uma massa cada vez maior de trabalhadores do mercado formal de trabalho, instaura um efeito imediato: o pauperismo. Este tem como fundamento a forma como o capital se apropria da força de trabalho mediante os mecanismos de exploração e de dominação, com o propósito de garantir a sua reprodução e a acumulação privada da riqueza, produzindo assim a acumulação da miséria na outra ponta. Essa é a lei geral da acumulação capitalista, que revela porque, nessa sociabilidade, riqueza e pobreza são polos indissociáveis de um mesmo processo.
} 
depender da fase de desenvolvimento que o capitalismo experimenta, perpassa pela pura repressão a medidas legislativas, através de programas e políticas sociais voltados para a desmobilização da classe trabalhadora.

Com a explosão da crise estrutural e a ativação do desemprego crônico disfarçado de práticas trabalhistas flexíveis, fragmentação e precarização da força de trabalho para garantia da máxima exploração administrável do trabalho, a principal consequência é a redução significativa do padrão de vida dos trabalhadores empregados e desempregados. Contudo, neste país, sempre se conviveu com o desemprego, com péssimas condições salariais e com a precarização do trabalho, portanto, essas características não são uma exclusividade dos impactos da crise estrutural e tendem a se agravar a partir dela.

Tais impactos começam a surgir no Brasil no final dos anos de 1990, quando se observa o início da flexibilização e da desregulamentação dos direitos sociais e trabalhistas, com a generalização da terceirização, da subcontratação, do trabalho domiciliar, das chamadas microempresas, da baixa remuneração da força de trabalho, com modalidades de salário por peça, salários por produção, acordos de banco de hora etc.

Diante disso, evidencia-se uma exploração cada vez maior dos trabalhadores e o deslocamento das responsabilidades sociais do Estado para a própria sociedade, com a crescente mercantilização de serviços, como saúde, educação e segurança, e a revogação gradual de direitos sociais que sequer chegaram a ser garantidos integralmente, minando também o surgimento de novos direitos. As políticas sociais destinam-se apenas àquelas pessoas em condição de miséria extrema. Com efeito, constata-se o aumento da desigualdade, da pobreza, do desemprego, da violência, da exclusão e a generalização da precarização do trabalho.

Dados divulgados pelo IBGE em 2017 revelam que 52,168 milhões de brasileiros - um quarto da população do país - estão abaixo da linha de pobreza. Destes, apenas 40,4\% teriam acesso à água, a esgoto e à coleta de lixo (INSTITUTO BRASILEIRO DE GEOGRAFIA E ESTATÍSTICA, 2017, p. 3). Outro dado relevante de 2018 diz respeito ao grave quadro de desemprego entre os jovens no país, de $26,6 \%$, enquanto que a taxa de desemprego da população em geral é de 12,4\% (INSTITUTO BRASILEIRO DE GEOGRAFIA E ESTATÍSTICA, 2018, p.33). Essa situação tende a se agravar nos anos subsequentes com os impactos do Teto dos Gastos públicos, que congelou os gastos sociais por vinte anos, da Reforma Trabalhista aprovada em 2017 e da Reforma da Previdência em andamento, medidas que acentuarão ainda mais a pobreza e a desigualdade social no país.

É nesse contexto que se inicia a tentativa do Estado de contenção das contradições imanentes ao sistema, das expressões da "questão social", que se acirram com a crise estrutural do capital e põem em risco a ordem estabelecida e os interesses das classes dominantes. A "questão social" continua a ser tratada como caso de política, mas com o predomínio da política repressiva, constante e acentuada. Não por acaso, as taxas de encarceramento no Brasil vêm aumentando desde 1990 e cresceram oito vezes até 2016, conforme o Gráfico 1. 


\section{Gráfico 1 - Evolução das pessoas privadas de liberdade entre 1990 e 2016}

\section{EVOLUÇÃO DAS PESSOAS PRIVADAS DE LIBERDADE ENTRE 1990 E 2016}

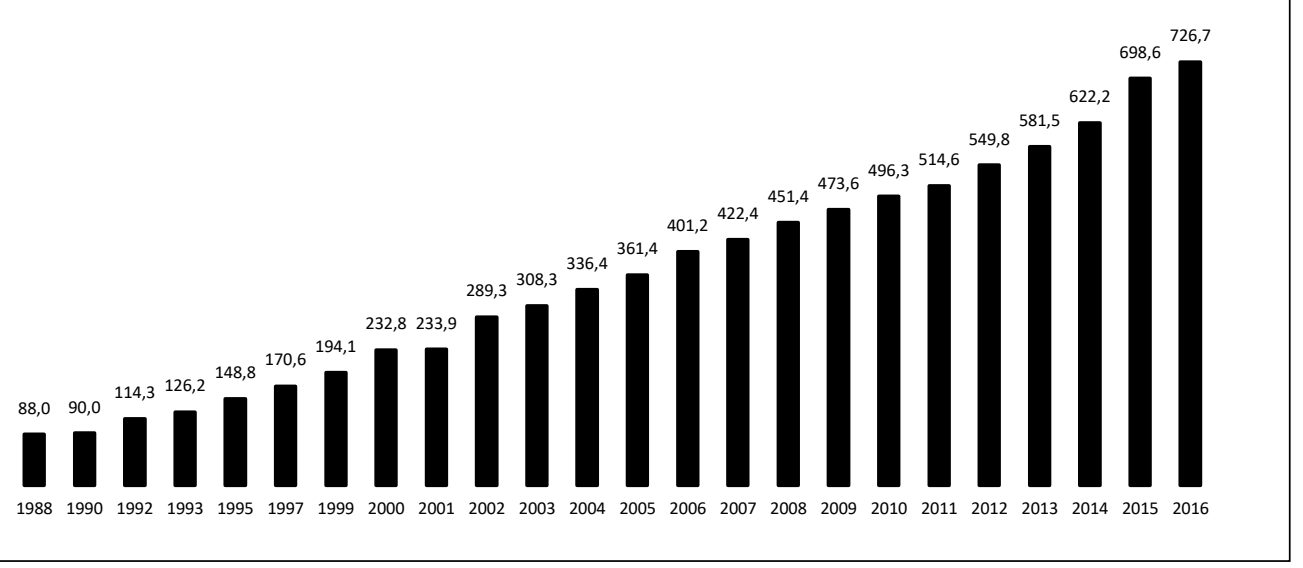

Fonte: Ministério da Justiça e Levantamento Nacional de Informações Penitenciárias - INFOPEN (2016).

Entre os anos 2000 e 2016, a taxa de aprisionamento aumentou em 157\% no país, colocando-o no ranking mundial como o terceiro país que mais encarcera no mundo e o único cuja população carcerária continua aumentando a cada ano. Essa cifra assustadora não revela o número exato de pessoas sob o controle do Estado, já que não se considera os que estão em prisão domiciliar e os monitorados eletronicamente.

Contudo, o alvo do Sistema Penal brasileiro é bastante delineado no Levantamento Nacional realizado em 2016: trata-se majoritariamente de jovens negros, com baixo grau de escolaridade, acusados de tráfico e de crimes patrimoniais, tendência que se confirma desde os primeiros relatórios. Os dados apontam que $55 \%$ da população prisional é formada por jovens até 29 anos, mas, se incluirmos aqueles que possuem até 34 anos, essa cifra se eleva para $74 \%$. Há ainda um aumento de $656 \%$ no número de mulheres encarceradas. No total, $64 \%$ da população prisional é formada por negros. No que se refere à escolaridade, observa-se que $80 \%$ não concluíram sequer o Ensino Médio.

A pesquisa releva também que 70\% dos homens encarcerados são acusados de tráfico ou crimes patrimoniais. Se levarmos em consideração os dados do IBGE - a população entre 18 e 29 anos representa apenas $18 \%$ da população total no Brasil, enquanto que a população negra acima de 18 anos representa 53\% dos brasileiros -, confirmaremos o prognóstico de sobrerrepresentação do jovem negro no sistema prisional.

Há que se destacar as condições subumanas a que são submetidos os encarcerados, pois o mesmo relatório revela uma superlotação prisional, com um deficit total de 358.663 mil vagas. Instituições superlotadas contribuem para as relações de violência e para o crescimento das facções criminosas, com estruturas físicas falhas, deficientes e inadequadas, que não oferecem o mínimo de privacidade aos detentos. As unidades prisionais brasileiras se destacam pela insalubridade e pela falta de higiene, o que favorece o surgimento de doenças físicas e mentais, e pela ausência de assistência aos encarcerados. 
Em junho de 2016, 40\% das pessoas encarceradas ainda não haviam sido condenadas ou julgadas, o que evidencia o mecanismo de isolamento, de depósito de pessoas indesejadas e supérfluas ao sistema no cárcere brasileiro. O encarceramento massivo, entretanto, não é a única forma repressiva de controle da pobreza no Brasil. São vários os exemplos e os mecanismos atuais de intensificação da repressão estatal: a criminalização de pessoas em situação de rua e a assepsia policial são exemplos das ações de limpeza realizadas pelo Estado. Na conhecida Cracolândia, em São Paulo, são constantes as tentativas de retirada de dependentes químicos sob a truculência da Polícia Militar, com a utilização de bombas, de gás de pimenta e balas de borracha, munições com menor potencial ofensivo, para dispersar os moradores, afirmam os policiais.

Por outro lado, o Anuário Brasileiro de Segurança Pública demonstra, com pequenas variações, expostas no Gráfico 2, o aumento da letalidade em intervenções policiais (em serviço ou fora de serviço): são 14 mortes por dia. Quase a totalidade - 93\% das vítimas registradas em boletins de ocorrência como "morte decorrente de intervenção policial” - era de homens, negros $(76,2 \%)$ e jovens, com idade entre 15 e 29 anos.

Gráfico 2 - Mortes decorrentes de intervenções policiais

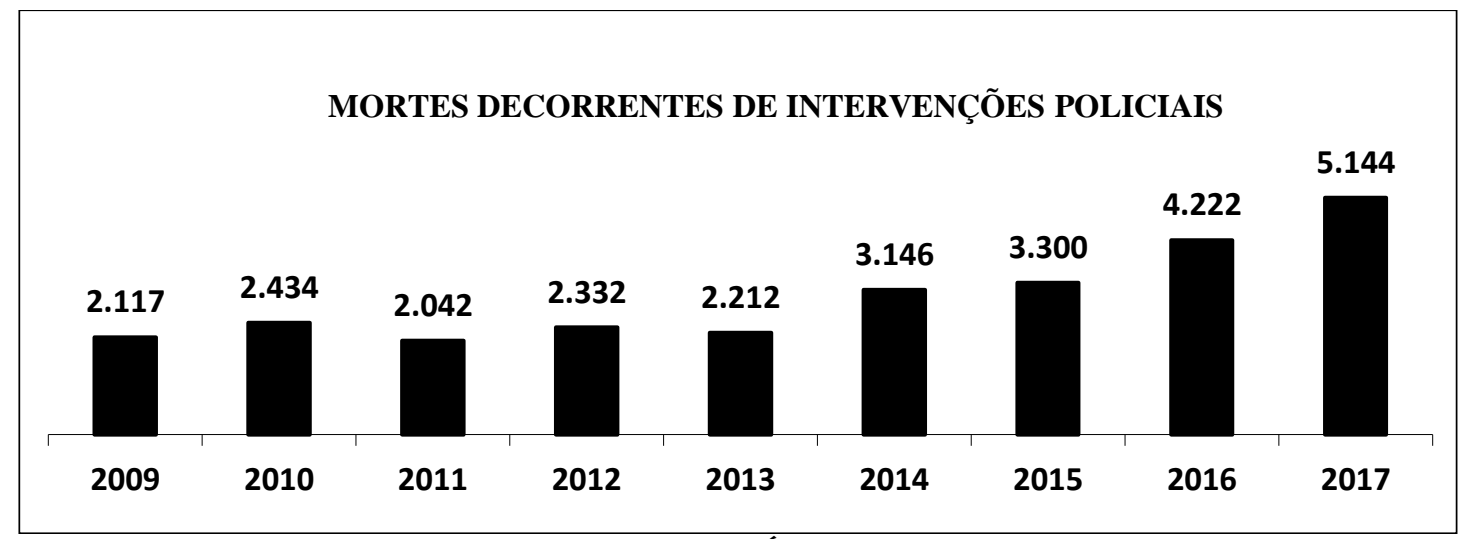

Fonte: Anuário Brasileiro de Segurança Pública (FÓRUM BRASILEIRO DE SEGURANÇA PÚBLICA, 2018, p. 26).

Além disso, há também um aumento constante de homicídios no Brasil, atingindo a marca 62.517 em 2016, número que se compara a guerras cívicas. $\mathrm{O}$ mais espantoso é que, dessa parcela assassinada, 33.590 são jovens entre 15 e 29 anos, 94,6\% são homens e 40,2\% são negros, moradores de periferias.

Esses dados refletem diretamente o impacto da escravidão e a desigualdade racial que deriva do processo de formação da sociedade brasileira, e que se mantém historicamente no Brasil. O fato de a seletividade social e étnico-racial do Estado ter sido mantida, e mesmo reforçada, confirma que a legislação e, portanto, a penalização não é uma lógica controladora em larga escala, que atravessa às cegas a sociedade para subjugar e prender seus diversos membros, pelo contrário, condiz com as necessidades do capital, de eliminação e contenção de uma população com perfil étnico, etário, educacional e socioeconômico pré-determinado, isto é, a população supérflua, os estratos mais empobrecidos e precarizados da sociedade brasileira, e, portanto, alvo da neutralização do Estado. Trata-se de uma verdadeira eliminação de parcelas 
indesejadas. Nesse contexto de crise econômica e de agravamento das tensões sociais no Brasil, o caso do Rio de Janeiro é emblemático, um claro exemplo da instabilidade social a que Mészaros se refere, com o aumento da criminalidade entre os jovens e constante ameaça de grandes agitações sociais. Sua situação não é exclusiva no país, mas se apresenta de modo especialmente grave, pois demonstra a incapacidade de conter ou mascarar o agravamento das contradições sociais, com o aumento exacerbado do crime organizado, mesmo diante das engenhosidades repressivas acionadas pelo Estado.

As informações do Fórum Brasileiro de Segurança Pública, no seu relatório Rio sob intervenção (2018), revelam que o corpo policial do estado do Rio de Janeiro desde 1990 executa corriqueiramente marginais e deliquentes; mortes relatadas oficialmente como atos de defesa e resistência, ou seja, legalmente praticadas. Dos 44 decretos da Garantia da Lei e da Ordem dos últimos 10 anos no Brasil, 17 ocorreram na cidade do Rio de Janeiro, mostrando o agravamento da militarização das favelas e de áreas populares da cidade, alvos de operações especiais do Estado (FÓRUM BRASILEIRO DE SEGURANÇA PÚBLICA, 2018, p. 11).

Um exemplo da intensificação da repressão estatal nas favelas é o Programa de Polícia Pacificadora, Decreto de no. 45.186, de 17 de março de 2015, que apresenta como objetivo "[...] a recuperação de territórios sob o controle de grupos ilegais armados, a restauração do monopólio legal e legítimo da força pelo Estado e a diminuição da criminalidade violenta, sobretudo a letal" (RIO DE JANEIRO, 2015). As áreas potencialmente contempláveis são, segundo o Decreto de no 42.787, "[...] aquelas compreendidas por comunidades pobres, com baixa institucionalidade e alto grau de informalidade, em que a instalação oportunista de grupos criminosos ostensivamente armados afronta o Estado Democrático de Direito" (RIO DE JANEIRO, 2011).

Conforme expõe Franco (2014), o programa das Unidades de Polícia Pacificadora (UPPs) não é para o conjunto da cidade, é um modelo de força de ocupação territorial voltado para as favelas, onde se concentram a miséria, a violência, as populações estigmatizadas, vistas como oposição ao conjunto da cidade, lugares potencialmente explosivos, por isso cria--se uma regulação diferenciada para controlá-los.

O que é vivido nesses territórios de permanência militar pode ser conceituado como uma 'guerra aos pobres'. [...] os 'territórios da pobreza' são tratados como 'território da violência'. A partir da 'guerra ao tráfico', legitima-se a guerra aos espaços populares, o que justifica as incursões militaristas que derramam de forma permanente o sangue dos moradores das favelas (FRANCO, 2014, p. 75).

Franco (2014) destaca, com base em dados do ISP, que entre 2007 e 2012 há um crescimento nos índices de desaparecimento nos territórios ocupados pelas UPPs, contrapondo o que se diz no decreto em relação à diminuição da criminalidade e à postura pacificadora da polícia comunitária, formada para tal função. A soma de casos de desaparecimento anteriores à instalação é de 85 pessoas, enquanto que no ano subsequente esse número se eleva para 133 pessoas.

Argum., Vitória, v. 12, n. 3, p. 43-57, set./dez. 2020. | ISSN 2176-9575 
A autora também identifica a ampliação da população carcerária dos moradores dessas favelas ocupadas (pobres e negros, em sua maioria) de um lado, e de outro, o isolamento dos territórios ocupados por esses sujeitos, concluindo que as UPPs não rompem com as marcas coercitivas do Estado. Por certo que não, afinal, esta é apenas mais uma medida encontrada pelo Estado para controle de áreas instáveis, através de um discurso de pacificação, de repressão à criminalidade, que legitima e vela a atuação crescentemente repressiva, assim como a perseguição e a eliminação de uma população potencialmente perigosa.

Ainda no espectro do Rio de Janeiro, há que se destacar a intervenção federal decretada no estado pelo ex-presidente Michel Temer, justificada como medida necessária e indispensável, para reforçar o combate ao crime organizado e restabelecer a segurança à população. A Constituição Federal de 1988 dispõe sobre a intervenção no Art. 34, definindo os casos em que pode ser realizada. É interessante destacar que a intervenção federal decretada em 16 de fevereiro de 2018 no Rio de Janeiro se fundamenta no inciso III do referido artigo, para "[...] pôr termo ao grave comprometimento da ordem pública” (BRASIL, 2020, p. 30). De fato, essa é a função do Estado, de mantenedor da ordem socialmente estabelecida, assegurando as condições externas para a acumulação capitalista.

Durante os 10 meses de intervenção, o monitoramento do Observatório da Intervenção apontou um aumento nos índices de violência e de confrontos entre facções, milícias e as forças de segurança. Nesse curto espaço de tempo, a cidade do Rio de Janeiro registrou um aumento de $58 \%$ no número de tiroteios e de $36,3 \%$ de mortes decorrentes de ação policial em relação ao mesmo período do ano anterior à intervenção. A Tabela 2 expõe a dimensão da violência empregada nas favelas do Rio de Janeiro durante a intervenção.

Tabela 2 - Intervenção federal no Rio de Janeiro

\begin{tabular}{c|c}
\hline Operações policiais-militares & 457 \\
\hline Agentes mobilizados & 200.000 \\
\hline Chacinas & 53 \\
\hline Mortes em chacinas & 213 \\
\hline Tiroteios & 8.183 \\
\hline Total de feridos & 1.090 \\
\hline Total de mortes & 1.203 \\
\hline
\end{tabular}

Fonte: Observatório da Intervenção ${ }^{3}$ (2018).

Frente à atual realidade brasileira, Alexandre de Moraes, ministro do Supremo Tribunal Federal (STF), entregou em 2018 um conjunto de propostas para recrudescimento da legislação penal no combate ao crime organizado, ao tráfico de drogas e de armas. Dentre as propostas elencadas, há o aumento do período máximo de cumprimento de pena na cadeia, de 30 para 40 anos, o enquadramento de crimes como tráfico de drogas e porte ilegal de arma de fogo de uso restrito na modalidade de

3 Esses dados correspondem ao período de 16 de fevereiro a 12 de dezembro de 2018.

Argum., Vitória, v. 12, n. 3, p. 43-57, set./dez. 2020. | ISSN 2176-9575 
crimes hediondos etc. Essas propostas foram incorporadas ao projeto de Lei Anticrime, apresentado pelo, na época, ministro da Justiça Sergio Moro e pela Frente Parlamentar da Segurança Pública, que traz medidas baseadas no modelo norte-americano - um dos países mais severos do ponto de vista repressivo - para assegurar o cumprimento da condenação após julgamento em segunda instância e mudanças para elevar as penas para crimes cometidos com armas de fogo.

Além desses, são inúmeros os projetos de lei em tramitação direcionados ao endurecimento na tipificação de crimes, ao aumento de penas e à exclusão do que consideram como benefícios aos apenados. É da chamada bancada da bala no Congresso Nacional, formada por militares, delegados e evangélicos de cunho extremamente conservador, de onde saem grande parte deles. Cabe destacar que essa bancada se ampliou significativamente nas eleições de 2018 , quando houve a maior candidatura de militares no país, elegendo nas Câmaras estaduais, federais e no Senado 72 militares, de quem se pode esperar posturas e projetos condizentes com os supracitados.

Acrescente-se que foram eleitos para a presidência do país os militares Jair Bolsonaro e Hamilton Mourão, candidatos com discurso autoritário, conservador e de defesa explícita da violência estatal voltada para as camadas pauperizadas da população brasileira, com amplo apoio popular. No seu governo, até agosto de 2020, das 21 pastas ministeriais do governo, 10 foram entregues para a gestão de militares, enquanto que pelo menos 254 cargos ministeriais comissionados foram ocupados por integrantes das forças armadas. Tais fatos são reflexo da tendência ao acirramento da postura repressiva estatal, através da multiplicação e do aprofundamento de medidas como o endurecimento da legislação, o encarceramento em massa, a declaração de guerra aos pobres, a penalização de favelados e de moradores de rua, a criminalização dos movimentos sociais e de trabalhadores informais, a truculência estatal e tantos outros dispositivos utilizados na atualidade.

Se há alguns anos foi possível extrair concessões significativas do capital, na medida em que os ganhos podiam ser assimilados pelo conjunto do sistema e integrados a ele, resultando em vantagens produtivas para o capital, agora, no contexto de crise estrutural, com o agravamento da "questão social", com destaque para o desemprego e a pobreza, a intensificação da repressão estatal tem sido um dos principais pilares de manutenção e reprodução do status quo. Por isso, identificamos na atualidade brasileira a tendência à prevalência de mecanismos repressivos sobre a parcela potencialmente explosiva da sociedade que vive na pobreza.

\section{Considerações finais}

Apresentados os determinantes econômicos, políticos e sociais da realidade brasileira contemporânea, conclui-se que a utilização intensa do aparato repressivo do Estado está vinculada à instabilidade provocada pelas transformações societárias desencadeadas pela crise estrutural do capital. O esgotamento da dimensão civilizatória do capital se expressa no crescimento da pobreza, na destruição do meio ambiente, na retirada de direitos conquistados, na precarização do trabalho, na

Argum., Vitória, v. 12, n. 3, p. 43-57, set./dez. 2020. | ISSN 2176-9575 
concentração de renda, na diminuição dos gastos sociais e na repressão sobre a pobreza e sobre movimentos sociais. Esses são exemplos das desumanidades que, sem expectativa de solução, tendem a se agravar ainda mais. Na verdade, são as velhas e novas expressões da "questão social”, geradoras de uma instabilidade social que não interessa ao sistema, porque vêm acompanhadas de consequências sociais que caracterizam um limite ao controle do capital.

Nesse contexto, as formas de administração da "questão social" outrora utilizadas tornaram-se estéreis. A partir de então, o Estado passa a abandonar a estratégia de consenso e passa a utilizar crescentemente a repressão como forma de controle da pobreza e de contenção das insatisfações sociais. Com efeito, a repressão estatal nada mais é do que uma das estratégias encontradas para administrar o acirramento das contradições sociais inerentes ao sistema que se agravam com a crise estrutural e afetam diretamente a classe trabalhadora e a sua camada pauperizada.

Em países periféricos como o Brasil, que sequer chegaram a vivenciar o padrão civilizatório europeu, as condições de vida e de trabalho da classe trabalhadora se mantiveram precárias. Portanto, frente à enorme desigualdade social e às parcas políticas sociais implementadas, o Estado brasileiro tem o desafio de controlar amplas camadas pauperizadas, a fim de garantir a manutenção da ordem necessária à acumulação do capital, por isso sua atuação tende a ser mais severa, utilizando de forma violenta e excessiva os mecanismos repressivos, como o encarceramento em massa, o recrudescimento da legislação e os outros mecanismos expostos para neutralizar uma população potencialmente perigosa: jovens, negros, pobres e favelados.

Diante disso, convém salientar que, na atualidade, a única alternativa à humanidade é o confronto direto ao capital. Por isso a necessidade de se resgatar a centralidade teórica e prática do trabalho, para que se rompa com as ilusões reformistas que ocultam as condições históricas de dominação do capital sobre o trabalho, recolocando em pauta a crítica ao Estado burguês como um ponto fundamental na luta dos trabalhadores para a transformação radical da sociabilidade capitalista e a construção de uma forma de sociabilidade humanamente emancipada.

\section{Referências}

BRASIL, Constituição (1988). Constituição da República Federativa do Brasil: texto constitucional promulgado em 5 de outubro de 1988, compilado até a Emenda Constitucional no 108/2020. - Brasília: Senado Federal, Coordenação de Edições Técnicas, 2020. Disponível em: https://livraria.senado.leg.br/constituicao-federal-108aemenda-livro-2020?search=constituição federal. Acesso em: 10 dez. 2020.

COSTA, Gilmaísa Macedo da. Pobreza e desemprego: a persistência de um fenômeno. In: JORNADA INTERNACIONAL DE POLÍTICAS PÚBLICAS, 3., São Luiz, 2007. Anais [...]. São Luís: Universidade Federal do Maranhão, 2007. Disponível em: http://www.joinpp.ufma.br/jornadas/joinppIII/html/Trabalhos/EixoTematicoC/821f315 4fic2881e5089Gilmaisa\%2oMacedo\%20da\%20Costa.pdf. Acesso em: 9 nov. 2018.

Argum., Vitória, v. 12, n. 3, p. 43-57, set./dez. 2020. | ISSN 2176-9575 
FÓRUM BRASILEIRO DE SEGURANÇA PÚBLICA. Anuário Brasileiro de Segurança Pública, ano 12, 2018. Disponível emhttps://forumseguranca.org.br/anuario-brasileiroseguranca-publica/ Acesso em: 10 dez. 2018.

FÓRUM BRASILEIRO DE SEGURANÇA PÚBLICA. Rio sob intervenção: por uma nova política de segurança pública. Rio de Janeiro, 2018. Disponível em: https://www.forumseguranca.org.br/wpcontent/uploads/2018/o4/FBSP_Rio_sob_Intervencao_2018_relatorio.pdf. Acesso em: 10 dez. 2020.

FRANCO, Marielle. UPP - A redução da favela a três letras: uma análise da política de Segurança Pública do Estado do Rio de Janeiro. 2014. Dissertação (Mestrado em Administração)-Universidade Federal Fluminense, Niterói, 2014.

INSTITUTO BRASILEIRO DE GEOGRAFIA E ESTATÍSTICA. Anuário Estatístico do Brasil (AEB). Rio de Janeiro, 2018. Disponível em:

https://biblioteca.ibge.gov.br/biblioteca-catalogo?id=720\&view=detalhes. Acesso em: 10 set. 2018.

INSTITUTO BRASILEIRO DE GEOGRAFIA E ESTATÍSTICA. Pesquisa Nacional por Amostra de Domicílios Contínua - PNAD Contínua: Informativo Rendimento de todas as fontes. Rio de Janeiro, 2017. Disponível em: https://biblioteca.ibge.gov.br/index.php/bibliotecacatalogo?view=detalhes\&id=2101559. Acesso em: 10 dez. 2020

NETTO, José Paulo. O Serviço Social e a tradição marxista. Revista Serviço Social e Sociedade, São Paulo: Cortez, ano 10, n. 30, p. 89-102, maio/ago. 1989.

MARX, Karl. O Capital. Vol. I. Tomo II. São Paulo: Nova Cultura, 1996. (Coleção Os economistas).

MESZÁROS, István. Para além do capital: rumo a uma teoria da transição. São Paulo: Boitempo, 2011.

\section{MINISTÉRIO DA JUSTIÇA E SEGURANÇA PÚBLICA E DEPARTAMENTO} PENITENCIÁRIO NACIONAL. Levantamento Nacional de Informações Penitenciárias Atualização - Junho de 2017. Brasília (DF): 2016. Disponível em: https://www.justica.gov.br>news>relatorio_2016_junho. Acesso em: 10 dez. 2018.

OBSERVATÓRIO DA INTERVENÇÃO. Infográfico 9. Disponível em: http://observatoriodaintervencao.com.br/. Acesso em: 8 out. 2018.

PANIAGO, Maria Cristina. A crise estrutural e a centralidade das classes sociais. Katálysis, Florianópolis, v. 17, n. 1, p. 41-49, jan./jun. 2014.

PIMENTEL, Edlene. Uma “nova questão social”? Raízes materiais e humano-sociais do pauperismo de ontem e de hoje. 2. ed. rev. São Paulo: Instituto Lukács, 2012. 
RIO DE JANEIRO. Decreto estadual № 42.787, de o7 de janeiro de 2o11. Dispõe sobre a implantação, estrutura, atuação e funcionamento das Unidades de Polícia Pacificadora (UPP) no estado do Rio de Janeiro. Rio de Janeiro, Rio de Janeiro, 7 jan. 2011. Disponível em: http://www.silep.planejamento.rj.gov.br/decreto 42787 o6o111.htm. Acesso em: 10 dez. 2018.

RIO DE JANEIRO. Decreto estadual № 45.186, de 17 de março de 2015. Regulamenta o Programa de Polícia Pacificadora no estado do Rio de Janeiro e determina outras providências. Rio de Janeiro, Rio de Janeiro, 18 mar.2015.

WACQUANT, Loïc. As duas faces do gueto. São Paulo: Boitempo, 2008.

WACQUANT, Loïc. As prisões da miséria. Rio de Janeiro: J. Zahar, 1999.

Nathália de Lourdes Fernandes CORREIA Trabalhou na concepção, delineamento, análise e interpretação dos dados e na redação do presente artigo.

Possui graduação em Serviço Social pela Universidade Federal de Alagoas (2016). Mestrado em Serviço Social pelo Programa de Pós-Graduação em Serviço Social/ PPGSS pela Universidade Federal de Alagoas (2018).

Reivan Marinho de SOUZA Trabalhou na concepção, delineamento, análise e interpretação dos dados e na redação do presente artigo.

Possui graduação em Serviço Social pela Universidade Federal de Alagoas (1987). Mestrado em Serviço Social pela Universidade Federal de Pernambuco (1998) Doutorado em Serviço Social pela Universidade Federal de Pernambuco (2006). Docente do curso de Serviço Social (1990) e do Programa de Pós Graduação em Serviço Social/ PPGSS da Universidade Federal de Alagoas (2007). Atualmente, Diretora da Faculdade de Serviço Social/ UFAL (Gestão 2018-2022). 